\title{
Assessment of Input Uncertainty by Seasonally Categorized Latent Variables Using
}

$5{ }^{1}$ Blackland Research and Extension Center, Texas A\&M Agrilife Research, 720 East Blackland

6 Road, Temple, Texas 76502, USA

$7 \quad 2$ Department of Hydraulic and Ocean Engineering, National Cheng Kung University, Tainan

$8 \quad$ City 70101, Taiwan

$9{ }^{3}$ Department of Water Resources Engineering and Conservation, Feng Chia University,

10 Taichung City 40724, Taiwan

$11{ }^{4}$ Aqua-Aerobic Systems, Inc., 6306 N Alpine Rd, Loves Park, Illinois 61111, USA

$12{ }^{5}$ Grassland, Soil \& Water Research Laboratory, USDA-ARS, 808 East Blackland Road, Temple,

13 Texas 76502, USA

14

$15 \dagger$ Corresponding author; email: haw.yen@gmail.com, hyen@brc.tamus.edu;

16 Tel: (254) 774-6004 


\section{Abstract}

18 Watershed processes have been explored with sophisticated simulation models for the past few

19 decades. It has been stated that uncertainty attributed to alternative sources such as model

20 parameters, forcing inputs, and measured data should be incorporated during the simulation

21 process. Among varying uncertainty sources, input uncertainty attributed to precipitation data

22 exhibits a dominant role, as it is the source driving most hydrologically-related processes. In

23 previous studies, latent variables (normally distributed random noise) have been implemented to

24 explicitly incorporate input uncertainty from precipitation data. However, it may not be

25 appropriate to apply the same set of latent variables throughout temporal series without

26 considering seasonal effects. In this study, seasonally categorized latent variables were defined to

27 investigate potential effects on model predictions and associated predictive uncertainty. Results

28 show that the incorporation of seasonal latent variables resulted in better statistical solutions

29 (NSE, Nash-Sutcliffe Efficiency coefficient) for both calibration ( 0.58 [streamflow] / 0.73 [sediment] /

$\left.300.59_{\text {[ammonia] }}\right)$ and validation $\left(0.57_{\text {[streamflow] }} / 0.45_{\text {[sediment] }} / 0.53_{\text {[ammonia] }}\right)$ periods. Alternative

31 definitions of Dry/Wet seasonality (two definitions are defined in this study) also affected model

32 predictions. In addition, it was determined that predictive uncertainty can be enhanced by

33 incorporating more latent variables during model calibration. The implementations of proposed

34 seasonal latent variables have further substantiated the importance of incorporating seasonal

35 effects when conducting comparable approaches. Applications of latent variables on future work

36 should evaluate potential effects on model predictions before performing associated scientific

37 studies or relevant decision making processes.

38 Keywords: Input uncertainty; Latent variables; Model calibration; IPEAT; SWAT 


\section{Introduction}

In the past two decades, sophisticated watershed simulation models have been developed to

41 investigate relevant issues of hydrologic and nutrient processes (e.g., Soil and Water Assessment

42 Tool, SWAT (Arnold et al., 2012); Agricultural Policy/Environmental Extender Tool, APEX

43 (Williams et al., 2012); and Hydrological Simulation Program-Fortran, HSPF (Bicknell et al.,

44 1997)). The associated high-dimensional calibration work required is challenging. The

45 uncertainty attributed to different sources such as model parameters, forcing inputs, and

46 measured data should be incorporated in hydrologic and nutrient modeling research (Balin et al.,

47 2010; Yen et al., 2014b). In addition, the issue of equifinality could also be a concern since

48 similar model predictions may be generated through alternative parameter sets (Beven, 2006;

49 Ficklin and Barnhart, 2014). While several studies have addressed the issue broadly (Wang et al.,

50 2014; White et al., 2015), additional detailed investigations have been conducted on specific

51 uncertainty sources including: parameters, forcing inputs, model structure, and measured

52 calibration/validation data (Ajami et al. 2007; Salamon and Feyen, 2009; Balin et al., 2010; Yen

53 et al., 2014b). Biased results, in terms of model predictions, are often generated when one or

54 more uncertainty sources are omitted during calibration. Consequently, prejudiced information

55 may lead to poor judgment during decision making activities (McMillan et al., 2011).

56 Among varying uncertainty sources, input uncertainty associated with precipitation data

57 exerts a significant role (Balin et al., 2010, McMillan et al., 2011). Precipitation data is typically

58 measured by tipping bucket rain gauges whereas mean areal precipitation records may be

59 comprised of both spatial and temporal data (Balin et al., 2010). Input data uncertainty associated

60 with precipitation may be caused by mechanical issues, evaporation losses, wind disturbance and

61 other random errors (McMillan et al., 2011). Most hydrological and nutrient processes are driven

62 by surface and subsurface flow resulting from precipitation. It is therefore difficult to provide 
63 reliable model predictions when input uncertainty associated with precipitation data is not

64 identified using scientifically credible approaches (McMillan et al., 2011).

65 Studies exploring uncertainty associated with precipitation data model input are still

66 uncommon. The mainstream approach implements latent variables, where input uncertainty

67 attributed to precipitation is incorporated explicitly, during the calibration process (Kavetski et

68 al. 2002; Ajami et al. 2007, Yen et al., 2015a). Precipitation data is altered by multiplying

69 random numbers (i.e., white noise) from a normally distributed pool with a pre-defined mean $(\mu)$

70 and variance $\left(\sigma^{2}\right)$. The mean and variance are calibrated, along with other model parameters, in

71 the following generation. The first use of latent variables assigned random numbers to each and

72 every time step of precipitation data (Kavetski et al. 2002; Kavetski et al. 2006). However, the

73 calibration requirements become extremely difficult with increasing data record length because

74 the number of parameters requiring calibration increases correspondingly. A more feasible

75 approach, proposed by Ajami et al. (2007), requires only a small set of latent variables (i.e.,

76 single values for both mean and variance) applied during the calibration process. The

77 justification for their default mean $(0.9$ to 1.1$)$ and variance $\left(10^{-5}\right.$ to $\left.10^{-3}\right)$ ranges is however

78 unexplained. Additionally, there is no guarantee that model predictions will be improved by

79 using these default settings. Yen et al. (2015a) investigated several alternative latent variable

80 ranges and found they altered the associated calibration and/or the uncertainty analysis results.

81 Latent variable use can provide more comprehensive knowledge on model predictions and

82 ultimately better guidance for decision making processes, however, more studies are required to

83 develop the method's robustness. For example, the seasonal effect of latent variables has not

84 been considered in other studies. The goal of this study was to explore the effect and magnitude

85 of latent variable applications upon model predictions by categorizing latent variables (i.e., 
86 precipitation data) on a seasonal basis. Two general questions were proposed: 1) does a single set

87 of latent variables, representing the whole simulation period provide statistically sufficient

88 results? and, 2) how much do model predictions results change when different sets of latent

89 variables are assigned? Specifically, the following objectives were examined: (i) quantify and

90 compare model predictions (streamflow rate, sediment, and ammonia loads) by implementing

91 different categories of latent variables; and (ii) quantify corresponding predictive uncertainty

92 while the latent variable approach is conducted to incorporate input uncertainty on precipitation

93 data. In this study, SWAT was employed, with precipitation latent variable scenarios, to conduct

94 watershed simulations for the Arroyo Colorado Watershed (ACW) in Texas, USA. Five

95 scenarios were examined and compared.

\section{Materials and Methods}

\section{2.1. The SWAT Model}

SWAT was developed in early 1990s by the United States Department of Agriculture -

99 Agricultural Research Service (USDA-ARS), Temple, Texas, to evaluate the impact of land

100 management on water, sediment and pollutant yields (Gassman et al., 2007; Arnold et al., 2012).

101 SWAT is a continuous hydrologic model that has the capability to run on a daily time-step at a

102 watershed scale. Major components of the SWAT model include surface runoff, return flow,

103 reach routing, meteorology, erosion, soil temperature, crop growth, nutrients, pesticides and

104 agricultural management. In addition, SWAT is a semi-physically based, spatially distributed

105 model that disaggregates the watershed into several hydrologic response units (HRUs) with

106 homogeneous land use, soil and topographic characteristics. Over the years, the SWAT model

107 has been successfully applied to model water quality issues including sediments, nutrients and 
108 pesticides in watersheds (Lin et al., 2013; Zhenyao et al., 2013; Yen et al., 2015b). More than 1092,000 peer-reviewed journal articles are available for users as references in implementing 110 relevant topics.

$111 \quad$ 2.2. Study Area \& Model Inputs

112 The study area was the Arroyo Colorado watershed (ACW) located in southern Texas 113 along the border of USA and Mexico (see Figure 1). The Arroyo Colorado River flows eastwards 114 to the Gulf of Mexico and drains the watershed with an area of $1,692 \mathrm{~km}^{2}$. The predominant land 115 use type in ACW is agriculture (54\%) and range land (18.5\%), followed by urban areas (12.5\%) 116 along the mainstream of the river. The soil types in the watershed are mostly clays, fine loams, 117 and clay loams (clay: $20.4 \%$, fine loam: $13.2 \%$, clay loam: $7.4 \%$, fine silt: $6.3 \%$, silty clay: $4.0 \%$, 118 fine clay: 4.0\%) with soil depths ranging between 1.6 and $2.0 \mathrm{~m}$ (USDA, 1972). The climate in 119 the watershed is semi-arid with annual precipitation ranging from about 530 to $680 \mathrm{~mm}$, and 120 mean monthly temperatures ranging from $14.5^{\circ} \mathrm{C}$ in January to $28.9^{\circ} \mathrm{C}$ in July.

$121 \quad$ Figure 1 shows spatial positions for three weather stations and a stream gauge. Daily 122 meteorological data including precipitation, minimum and maximum air temperature were 123 compiled from these three stations covering 2000 to 2005. This meteorological data was obtained 124 from Texas State Climatologist Office located at Texas A\&M University at College Station. 125 International Boundary and Water Commission provided daily streamflow data for two stations, 126 one near the estuary of the river and the other near Llano Grande at middle of the reach. 127 Streamflow data near the estuary is influenced by the diurnal fluctuations of tidal waves. 128 Therefore, 2002 to 2005 streamflow data from the station near Llano Grande (marked in Fig. 1) 129 was used to calibrate the SWAT model. 
A digital elevation model, with a resolution of 30 meters, was downloaded from the

131 National Elevation Dataset of the U.S. Geological Survey (USGS) (Gesch et al., 2009)

132 (accessible online at http://ned.usgs.gov/; last accessed on September 18, 2013). Land use data

133 was created from remote sensing data and field surveys for 2004 to 2007 were used to represent

134 land cover conditions. Soil properties were acquired from the SSURGO soil database of USDA-

135 NRCS (Natural Resources Conservation Service). Based on the topography and river network, 136 the ACW was divided into 17 subbasins. The subbasins were further partitioned into 475 HRUs

137 according to the land use and soil properties.

138 The ACW has 21 permitted point source discharges, 16 of which are municipal, three are

139 industrial, and two are shrimp farms. The discharge permit limits the municipal plants range

140 from 0.4 to 10 million gallons per day. The shrimp farms discharge infrequently (Rains and

141 Miranda, 2002). Water quality data from limited grab samples were obtained for suspended

142 sediment (SS) and ammonia (NH4+-N). The grab-samples were converted, using the Maximum

143 Likelihood Estimation (MLE) method, to time series load by the LOAD ESTimator (LOADEST)

144 developed by USGS (Runkel et al. 2004). The time series water quality data, with monthly

145 average within $95 \%$ confidence interval, was used as observation data for calibration of the

146 SWAT model. Additional ACW details can be found in Seo at al. (2014).

\section{$147 \quad$ 2.3. Examining Input Uncertainty using Seasonally Defined Latent Variables}

148 In general, "forcing inputs" consist of data that exert critical control on model simulations.

149 Classic examples include precipitation and temperature. More and more studies have taken the 150 approach of using latent variables to incorporate forcing input uncertainty explicitly into 151 watershed modeling (Kavetski et al., 2002; Ajami et al., 2007; Yen et al., 2015a). The original 152 scheme of implementing input uncertainty, proposed by Kavetski et al. (2002) (Bayesian total 
153 error analysis, BATEA), assigns latent variables to each time step. It starts from pre-defined,

154 estimated, values which are calibrated, along with other model parameters. In this case, the 155 number of latent variables, and associated calculations, increases rapidly, thereby complicating

156 the modeling process. An alternative approach, developed by Ajami et al. (2007) (Bayesian 157 uncertainty estimator, IBUNE), applies one set of latent variables throughout the entire 158 simulation period. In this study, precipitation was chosen as the source of input uncertainty and 159 the associated equation is shown as follows:

$$
R_{i}^{\text {adjusted }}=k \times R_{i}^{\text {observed }}
$$

Where, $R_{i}^{\text {adjusted }}$ is the adjusted precipitation $(\mathrm{mm}) ; R_{i}^{\text {observed }}$ is the observed precipitation

$162(\mathrm{~mm})$; and $k$ is a normally distributed random number or noise with latent variables mean $(\theta)$

163 and variance $\left(\sigma^{2}\right)$. In this study, input uncertainty settings use the approach implemented in

164 IBUNE, latent variables are predefined parameters which require further calibration within the 165 specific ranges; $\theta \in[0.9 \sim 1.1] ; \sigma^{2} \in\left[10^{-5} \sim 10^{-3}\right]$.

\subsection{Case Scenario Descriptions}

167 The input uncertainty scheme used in IBUNE assumes that latent variables are applied 168 uniformly throughout a simulation period. However, it may not be reasonable to apply the same 169 set of latent variables without considering seasonal effects upon model predictions. In this study, 170 two seasonal definitions were considered. Definition I averages monthly precipitation data 171 combined from three gauge stations (Figure 2A). Definition II averages monthly precipitation

172 from individual stations (Figures 2B, 2C, and 2D). The definition of wet and dry seasons can be

173 subjective. In this study, the three rain gauges in the watershed each show distinct patterns of 174 monthly average precipitation. Accordingly, dry and wet seasons are defined at each individual 
175 gauge station according to monthly precipitation (Figure 2). The six months with the highest

176 precipitation comprise the wet season, while dry season consists of the remaining months. Latent

177 variables were implemented based on whether dry or wet seasons are defined by individual

178 gauge stations or as an average of all three gauge stations.

179 A total of five different model scenarios were evaluated (Table 1). Scenario 01 did not

180 utilize latent variables. Scenario 02 followed standard latent variable usage defined by Ajami et

181 al. (2007). Scenarios 03 and 04 implemented two sets of latent variables and two Dry/Wet season

182 definitions. In Scenario 04, Dry/Wet seasons are defined using Definition II. Monthly 183 precipitation from individual gauges provides more rigorously defined Dry/Wet seasons.

184 However, there are still only two sets of latent variables assigned for Dry/Wet seasons, but

185 different stations have different months categorized into Dry or Wet seasons. In Scenario 05,

186 Definition II is used and precipitation data from each gauge station is assigned independent sets

187 of latent variables. In this case, a total of six latent variable sets are implemented for varying 188 gauge stations, and Dry/Wet seasons. By comparing different definitions of Dry/Wet seasons and 189 precipitation averages (combined or individual stations), the potential impact on model 190 predictions, caused by seasonal effects, can be further explored.

\section{$191 \quad$ 2.5. Model Calibration/Validation}

192 The SWAT model calibration was conducted using Integrated Parameter Estimation and 193 Uncertainty Analysis Tool (IPEAT), developed by Yen et al. (2014b). IPEAT uses a 194 Dynamically Dimensioned Search (DDS) (Tolson and Shoemaker, 2007) to perform an auto195 calibration process. DDS is an implementation of the Bayes theorem that has been shown to 196 deliver superior solutions and convergence speed performance (Yen et al., 2014a) over other 197 widely-applied algorithms such as DiffeRential Evolution Adaptive Metropolis (DREAM) 
198 (Vrugt et al., 2009), Shuffle Complex Evolution (SCE-UA) (Duan et al., 1992), and Metropolis199 Hastings algorithm (MHA) (Metropolis et al., 1953). IPEAT has been implemented on large200 scale, high-resolution watershed modeling efforts in prediction of streamflow, sediment loads, 201 and nutrient losses such as the Conservation Effects Assessment Project - Wildlife (The Nature 202 Conservancy, 2014). The framework of IPEAT and the incorporation of input uncertainty, on 203 precipitation data, are shown in Figure 3. The calibration and validation periods of ACW are 204 from 2002 to 2003 and from 2004 to 2005 respectively. Data from years 1999 to 2000 were 205 utilized for model "warm up". Daily streamflow, monthly sediment load, and monthly ammonia 206 load output responses were utilized for model calibration/validation. As the ACW is close to the 207 Gulf of Mexico, ocean tides (e.g., periodical waves or diurnal fluctuations) exert a direct effect 208 upon measured observation data. In this case, observation ammonia data measured at the 209 southernmost station near Weslaco (near Llano Grande at FM 1015) was used to minimize tidal 210 effect.

211 The Nash-Sutcliffe Efficiency coefficient (NSE, Nash and Sutcliffe, 1970) was used to 212 formulate the objective function during model calibration. NSE is a broadly implemented 213 statistical measurement (ASCE 1993; Servat and Dezetter 1991) with potential ranges from $-\infty$ to 214 one (note: perfect match is indicated between observed and simulated responses when NSE 215 equals one). As suggested in previous work (Seo et al., 2014), the objective function is revised 216 for the model calibration and must be minimized in order to perform the automated calibration 217 process. In Equation (2), $y_{i}^{O b s}$ is the observation data at time step $i ; y_{i}^{S i m}$ is the simulated model 218 responses at time step $i ; y_{i}^{\text {Mean }}$ is the averaged observation data at time step $i$; and $N$ is the total 219 time steps.

$$
N S E=1-\frac{\sum_{i=1}^{N}\left(y_{i}^{\text {Obs }}-y_{i}^{S i m}\right)^{2}}{\sum_{i=1}^{N}\left(y_{i}^{\text {Obs }}-y_{i}^{\text {Mean }}\right)^{2}}
$$


222 The revised objective function is shown in Equation (3). Where: $O F$ is the aggregated 223 objective function; $N S E_{v}$ is the NSE value of output variable $v$ (e.g., streamflow rate, sediment 224 load, and ammonia losses in this study); and $V$ is the total number of output variables (e.g., $225 V=3$ in this study). The best possible value of the objective function is zero when all $N S E_{v}$ are 226 equal to one. To calibrate streamflow, sediment, and ammonia processes, 23 parameters were 227 included in auto-calibration of all case scenarios. Model parameters and the recommended 228 ranges are presented in Appendix A.

229 In this study, the Relative Percentage Difference (RPD) is defined to provide supplementary 230 indices in categorizing relative differences among various statistical results. By the use of RPDs, 231 users may have better understanding in making decisions upon available scenarios. RPDs among 232 individual variables (streamflow, sediment, NH4) and scenarios (1-5) were calculated as:

$$
R P D(\%)=\frac{\left|V_{1}-V_{2}\right|}{\frac{V_{2}+V_{1}}{2}} * 100
$$

Where, $V_{1}$ is the NSE result of an individual scenario; $V_{2}$ is the best NSE result among all 235 scenarios. The value of RPD is zero when the current state represents the best scenario. In 236 addition, uncertainty analysis was conducted after the statistical evaluations. In this study, 237 inclusion rate and spread are used to identify the relative level of uncertainty in each scenario. 238 Inclusion rate is the percentage of observation data falling within a $95 \%$ confidence interval of 239 simulated outputs. Spread is the average width of the $95 \%$ confidence interval along simulation 240 time series. Relevant details can also be found in Yen et al. (2014b). 


\subsection{Behavior Definition}

242 To explore the quality of model predictions in different applications of latent variables, the

243 General Performance Ratings (GPR) was implemented to assess the success rate of calibration

244 results (details of GPR can be found in Moriasi et al., 2007). GPR is currently considered to be

245 the most widely accepted statistical guideline (or behavior definition) in the field of water

246 resources and agricultural engineering (more than 1,900 citations since 2007). In this study,

247 results of model predictions can be characterized into conceptual categories such as Satisfactory

248 (NSE $>0.5)$ and Unsatisfactory $(\mathrm{NSE} \leq 0.5)$.

\section{3. Results and Discussion}

\section{3.1. General Comparisons of Model Performance}

251 The general performance (convergence of objective function values versus model iterations),

252 of all scenarios, is shown in Figure 4. The auto-calibration convergence patterns were similar for 253 each scenario after $\sim 3,000$ runs and final objective function values were limited to a range of 2541.19 to 1.40 (Scenario 01: 1.19; Scenario 02: 1.29; Scenario 03: 1.33; Scenario 04: 1.29; 255 Scenario 05: 1.40;). This result was not unexpected as Yen et al. (2015a) found latent variable 256 variation does not considerably alter the final converged values of the objective function.

257 Model statistics were evaluated by considering NSE values and RPD, among 258 calibration/validation periods and precipitation scenarios. Results are summarized in Table 2. 259 NSE values $>0.5$ were considered acceptable (Moriasi et al. 2007) with the scenario closest to 1 260 considered best. In general, NSE values were $>0.5$ for all variables and scenarios in the 261 calibration period. In the validation period, NSE values were mostly lower than 0.6 especially in 262 sediment and $\mathrm{NH}_{4}$ predictions. In comparing each case scenario for the calibration period, 
263 Scenario 02 performed the best in two of three variables (NSE $=0.61$ and 0.64 for streamflow 264 and $\mathrm{NH}_{4}$ ) where Scenario 01 generated the better performance for sediment (NSE=0.78).

265 However, statistical differences in the calibration period are not far apart among all scenarios and 266 output variables. RPD for streamflow, sediment, and $\mathrm{NH}_{4}$ is only $12 \%, 7 \%$, and $13 \%$, which 267 indicating compatible performance in terms of model predictions. In the validation period, 268 Scenario 05 outperformed other scenarios in all output variables $(\mathrm{NSE}=0.57,0.45$, and 0.53 for 269 streamflow, sediment, and $\mathrm{NH}_{4}$ ). RPD for streamflow (15\%) is still not showing substantial 270 difference, however, much higher RPD was derived for sediment (50\%) and $\mathrm{NH}_{4}(64 \%)$.

271 By using the default settings of latent variables defined by Ajami et al. (2007), the best 272 results were delivered for two of the three variables. However, Scenario 02 also generated the 273 worst statistical results for the validation period. On the other hand, Scenario 05 provided 274 compatible results in both calibration and validation periods in all three output variables 275 evaluated. Overall, Scenario 05 that incorporated seasonal effect from multiple stations provided 276 the best solution. As mentioned previously, variation did not considerably alter the final 277 converged values of the objective function because the objective function was insensitive to the 278 use of latent variables (Yen et al., 2015a). In addition to NSE for evaluation, percent bias 279 (PBIAS) was also calculated for each scenario (as supplementary information) and showed fairly 280 consistent results. Scenario 02 performed well in the calibration period but was the worst in 281 validation; however, Scenario 05 performed well in both calibration and validation periods 282 compared to other scenarios. In the calibration period, PBIAS (\%) for Scenario 01 05 are $28310.31 / 13.15 / 19.44 / 19.47 / 13.30$ (streamflow), 15.52/11.06/12.93/16.93/11.43 (sediment), and 284 2.60/1.15/4.39/3.14/3.81 (ammonia). In the validation period, PBIAS (\%) for Scenario 01 05 are $28526.37 / 28.70 / 28.39 / 30.79 / 22.28$ (streamflow), 22.42/28.45/27.46/26.63/21.13 (sediment), and 
287 significant as those in NSE, but they do demonstrate the advantage of Scenario 05.

288 As mentioned previously that model performance can also be grouped into different 289 categories by pre-defined statistical threshold such as GPR by Moriasi et al. (2007). Calibration 290 results were grouped into two major clusters in Figure 5. It is clear to see that the use of default 291 latent variables (Scenario 02 by Ajami et al. (2007)) has provided considerably more results 292 within the Unsatisfactory category. Percentage of behavior solutions between Scenario 03 and 04 293 was not far apart from Scenario 01 without any latent variables applied. In addition, Scenario 05 294 again deployed better performance in terms of more behavioral solutions. As mentioned 295 previously, statistical results in the calibration period are relatively comparable in all scenarios 296 but not the same case for validation (Scenario 05 performed the best in the validation period). By 297 the application of GPR, the use of seasonally categorized latent variables (with detailed 298 definition of Dry/Wet seasons) can not only provide a better single solution, but it can also 299 generate more quality results in the targeted watershed.

300 The results show that Scenario 02, using default latent variable settings, was less stable than 301 other scenarios considering seasonal effect. Therefore, the application of Ajami et al. (2007) 302 defined latent variable default settings, without considering seasonal effect, may be questionable. 303 Also, combining latent variables with seasonal effects can produce better model responses in 304 impulsive hydrological cycles such as peak flow in spring or summer. It may also imply that 305 other sources of uncertainty, such as precipitation, temperature, etc., should be considered 306 simultaneously for future investigation. 


\subsection{Evaluation of Latent Variables and the Adjusted Precipitation Data}

308 Latent variable convergences $(\theta)$ are shown in Figure 6(A), 6(B), 6(C), 6(D), and 6(E).

309 Variances $\left(\sigma^{2}\right)$ are not presented, due to their minimal effect on model predictions (Yen et al.,

310 2015a)). Scenario 01 did not apply latent variables to seasonality (Figure 6(A)). The converged

311 value of $\theta$ is 1.01 throughout the simulation time series indicating precipitation data, for all time

312 periods, increased slightly. Figure 6(B) and 6(C), utilized the same number of latent variables

313 (four each) with differing definitions of Dry/Wet seasonality (I \& II). In these two scenarios,

314 latent variable $\theta$ converged to similar values in the dry season $\left(\theta_{D r y}^{\text {Scenario } 03}=1.075\right.$;

$\left.315 \theta_{D r y}^{\text {Scenario 04 }}=1.088\right)$ but not in the wet season $\left(\theta_{\text {Wet }}^{\text {Scenario 03 }}=0.902 ; \theta_{\text {Wet }}^{\text {Scenario 04 }}=1.077\right)$. The sum of

316 adjusted precipitation data in Scenario 03 should therefore be higher than Scenario 02 (also see

317 Figure 7(A)). In Figure 6(D), 6(E), and 6(F), three sets of latent variables were assigned to each

318 precipitation gauge station (G01, G02, and G03). G01 and G03 have similar latent variables

319 convergence (Dry season: $\theta_{D r y, G 01}^{\text {Scenario } 05}=1.020, \theta_{D r y, G 03}^{\text {Scenari } 05}=1.039$; Wet season: $\theta_{\text {Wet }, G 01}^{\text {Scenario } 05}=0.982$,

$\left.320 \theta_{W e t, G 03}^{\text {Scenario } 05}=1.001\right)$ where precipitation data was adjusted, within limited order. Dry/Wet season

321 latent variables exhibit substantial differences at $\operatorname{G02}\left(\theta_{D r y, G 02}^{\text {Scenario } 05}=1.093 ; \theta_{\text {Wet }, G 02}^{\text {Scenario } 05}=0.909\right)$

322 where precipitation values increased after convergence (Figure 7(B)).

323 Results showed the dry season latent variable $\theta$ has consistently higher values than the wet

324 season, regardless of seasonal definition (i.e., I or II). Different definitions in categorizing

325 Dry/Wet seasons while implementing latent variables will cause impact on precipitation data and

326 the associated model predictions. It also indicates that precipitation data in the dry period tends

327 to be adjusted more than the wet period. Definition I that categorizes Dry/Wet seasons by 328 averaged precipitation data in all stations cannot reveal the regional characters among varying 
329 stations. Latent variables for G02 are noticeably different than G01 or G03 (See Figure 6(D),

$3306(\mathrm{E})$, and $6(\mathrm{~F})$ ). The drawback of combining latent variables (non-seasonal effect considered,

331 single set of latent variables for all stations) may become a major concern in watersheds with

332 gauge stations located far apart.

\section{$333 \quad$ 3.3. Applications of Latent Variables and Uncertainty Analysis}

334 Latent variable use not only affects overall model predictions but the predictive uncertainty

335 as well. Quantifying predictive uncertainty magnitude is not straightforward and requires further

336 evaluation. In this study, inclusion rate and spread were used to perform uncertainty analysis in

337 each scenario. The unit of inclusion rate is percentage whereas the spread units should reflect

338 output response units (i.e., $\mathrm{m}^{3} / \mathrm{s}$ for streamflow, etc.). High inclusion rates, or low spreads,

339 represent a lower level of predictive uncertainty. However, it is not definitive that one watershed

340 modeling result uncertainty is more or less superior to another. Quantified uncertainty analysis

341 simply provides supplemental information to assist scientists or decision makers in the decision

342 making process.

343 As shown in Table 3, substantial influences of uncertainty in terms of inclusion rate and

344 spread, attributed to seasonal latent variable use, was noted in streamflow predictions and

345 reflected in ammonia and sediment predictions. This may be because streamflow responses are

346 directly associated with precipitation data. Also, uncertainty magnitude is correlated with the

347 number of latent variables used. In general, higher uncertainty is expected with the incorporation

348 of seasonal latent variables and scenarios with more latent variables exhibit higher levels of

349 predictive uncertainty. Therefore, Scenario 03 and 04 have more uncertainty than Scenario 02

350 and Scenario 05 uncertainty is higher than all other scenarios. One of the major reasons to

351 incorporate input uncertainty during calibration process is because it has been shown to be 
352 inappropriate by not considering other uncertainty sources while conducting watershed modeling

353 (Ajami et al., 2007). On the other hand, it is still not clear how to alleviate the impact on model

354 predictions by including other sources either. Intuitively, the incorporation of input uncertainty

355 using seasonally categorized latent variables should increase predictive uncertainty since more

356 variables are involved (which is true in this study). However, more impact can be found to be

357 placed on streamflow predictions instead of sediment and ammonia. This important finding has

358 pointed out a good direction for future work whereas more studies are required to further verify

359 the statement.

\section{4. Conclusion}

In this study, seasonal latent variables were applied to input uncertainty, in the form of

362 precipitation data, to determine the effect on model predictions and the associated predictive

363 uncertainty. Latent variable applications, without considering seasonal effects, produced

364 reasonable statistical solutions for the calibration period but not for the validation period. The

365 use of seasonal latent variables resulted in better statistical solutions for both calibration and

366 validation periods. Also, varying Dry/Wet seasonality definitions affected model predictions as

367 well. It is, however, difficult to judge whether a higher level of uncertainty is better than a lower

368 level. Scientists and engineers generally prefer to evaluate model simulations for a long term

369 period to ensure the quality of model predictions. In the case study at the Arroyo Colorado

370 Watershed, four years of data are available for calibration and validation periods on streamflow,

371 sediment, and ammonia outputs. However, it is not clear whether the results will be affected

372 because the approach proposed in this study is not based on how well the model represents the

373 hydrologic system, but how different schemes of latent variables affect model optimization.

374 More studies should be conducted to address detailed evaluations on predictive uncertainty. 
375 In previous studies, the use of latent variables was shown to have improved model 376 predictions compared to those not considering input uncertainty on precipitation data (Ajami et

377 al., 2007). The use of latent variables does not guarantee better statistical solutions if not applied

378 in the default settings (Yen et al., 2015a). In this study, seasonal latent variables demonstrated 379 the importance of seasonal effects by comparing differing input data combinations. Meanwhile, 380 the approach performed in this study represented as a semi-arid watershed. Future work can be 381 further conducted on less or more humid regions to compare differences and the associated 382 impacts toward model predictions. Implementations of latent variables on future work should 383 pre-verify the potential impact towards model predictions before performing associated scientific 384 studies or relevant decision making processes. 


\section{References}

Ajami, N. K., Q. Duan, S. Sorooshian, (2007). An integrated hydrologic Bayesian multimodel combination framework: Confronting input, parameter, and model structural uncertainty in hydrologic prediction. Water Resources Research, 43(1), pp.1-19.

Arnold, J., D. Moriasi, P. Gassman, K. Abbaspour, M. J. White, R. Srinivasan, C. Santhi, R. D. Harmel, A. van Griensven A., M. W. van Liew, N. Kannan and M. K. Jha, (2012). SWAT: Model use, calibration, and validation. Transactions of the ASABE. 55(4): 1491-1508.

ASCE, (1993). Criteria for evaluation of watershed models, ASCE task committee on definition of criteria for evaluation of watershed models of the watershed management, irrigation, and drainage division. Journal of Irrigation and Drainage Engineering. 119(3): 429.

Balin, D., Lee, H., Rode, M., (2010). Is point uncertain rainfall likely to have a great impact on distributed complex hydrological modeling. Water Resources Research, 46: doi: 10.1029/2009WR007848. issn: 0043-1397.

Beven K.J., (2006). A manifesto for the equifinality thesis. Journal of Hydrology 320: 18-36.

Bicknell, B. R., Imhoff, J. C., Kittle, Jr. JL., Donigian, A. S., Johanson, R. C., (1997). Hydrological Simulation Program--Fortran: User's manual for version 11. U.S. Environmental Protection Agency, National Exposure Research Laboratory, Athens, GA, EPA/600/R-97/080. 755 p.

Clark, M. P., Slater, A. G., Rupp, D. E., Woods, R. A., Vrugt, J. A., Gupta, H. V., Wagener, T., Hay, L. E., (2008). Framework for Understanding Structural Errors (FUSE): A modular framework to diagnose differences between hydrological models. Water Resources Research, 44, pp.1-14.

Duan, Q., Sorooshian, S., Gupta, V., (1992). Effective and efficient global optimization for conceptual rainfall-runoff models. Water Resources Research, 28(4), pp.1015-1031.

Ficklin, D. L., and B. L. Barnhart, (2014). SWAT hydrologic model parameter uncertainty and its implications for hydroclimatic projections in snowmelt-dependent watersheds. Journal of Hydrology. 519, 2081-2090.

Gassman, P. W., Reyes, M. R., Green, C. H., Arnold, J. G., (2007). The soil and water assessment tool: historical development, applications and future research directions, Transactions of the American Society of Agricultural and Biological Engineers 50 (4), 1211-1250.

Gesch, D., Evans, G., Mauck, J., Hutchinson, J., Carswell, Jr, W. J., (2009). The National MapElevation: U.S. Geological Survey Fact Sheet 2009-3053, 4 p. Last accessible online at http://ned.usgs.gov/; last accessed on September 18, 2013.

Kavetski, D., Franks, S. W., Kuczera, G., (2002). Confronting input uncertainty in environmental modeling. Water Science and Application 6, pp.49-68.

Kavetski, D., G. Kuczera, and S. W. Franks, (2006). Bayesian analysis of input uncertainty in hydrological modeling: 1. Theory, Water Resources Research, 42(3), 1-9.

Lin, S., Jing, C., Coles, N. A., Chaplot, V., Moore, N. J., Wu, J., (2013). Evaluating DEM source and resolution uncertainties in the Soil and Water Assessment Tool. Stochastic Environmental Research and Risk Assessment, 27(1), 209-221. doi: 10.1007/s00477-0120577-x 
Loosvelt, L., Pauwels, V. R. N., Cornelis, W. M., De Lannoy, G. J. M., Verhoest, N. E. C., (2011) Impact of soil hydraulic parameter uncertainty on soil moisture modeling. Water Resources Research, 47(3), pp.1-16.

McMillan, H., Jackson, B., Clark, M., Kavetski, D., Woods, R., (2011). Input Uncertainty in Hydrological Models: An Evaluation of Error Models for Rainfall . Journal of Hydrology 400(1-2): 83-94.

Metropolis, N., A. W. Rosenbluth, M. N. Rosenbluth, A. H. Teller, E. Teller, (1953). Equations of state calculations by fast computing machines, Journal of Chemical Physics, 21(6), 10871092.

Nash, J. E. and J. V. Sutcliffe (1970), River flow forecasting through conceptual models part I A discussion of principles, Journal of Hydrology, 10 (3), 282-290.

Rains, T. H., Miranda, R. M., (2002). Simulation of Flow and Water Quality of the Arroyo Colorado, Texas, 1989-99, United States Geological Survey-Water Resources Investigations Report, No: 02-4110.

Runkel, R., Crawford, C., Cohn, T., (2004). Load Estimator (LOADEST): A Fortran Program for Estimating Constituent Loads in Streams and Rivers 2004. US Geological Survey Techniques and Methods Book, 4.

Salamon, P., Feyen, L., (2009). Assessing parameter, precipitation, and predictive uncertainty in a distributed hydrological model using sequential data assimilation with the particle filter. Journal of Hydrology, 376, 428-442, doi:10.1016/j.jhydrol.2009.07.051.

Seo, M. J,, Yen, H., Jeong, J., (2014). Transferability of input parameters between SWAT 2009 and SWAT 2012. Journal of Environmental Quality, 43, pp. 869-880. doi: 10.2134/jeq2013.11.0450.

Servat, E. and A. Dezetter., (1991). Selection of calibration objective functions in the context of rainfall-runoff modeling in a Sudanese savannah area. Hydrological Sciences Journal. 36(4): pp.307-330.

The Nature Conservancy, (2014). WLEB CEAP Report October 2014. Western Lake Erie Basin Conservation Effects Assessment Project. available at: http://lakeerieceap.com/resources/

Tolson, B. A., Shoemaker, C. A., (2007) Dynamically dimensioned search algorithm for computationally efficient watershed model calibration. Water Resources Research, 43(1), pp.1-16.

USDA-SCS (1972) National Engineering Handbook, Hydrology, Section 4, Chapter 4-10. Washington, D. C.: Soil Conservation Service.

Vrugt, J. A., Braak, C. J. F., Diks, C. G. H., Robinson, B. A., Hyman, J. M., Higdon, D., (2009) Accelerating Markov Chain Monte Carlo Simulation by Differential Evolution with SelfAdaptive Randomized Subspace Sampling. International Journal of Nonlinear Sciences \& Numerical Simulation, 10(March), pp.271-288.

Wang, X., H. Yen, J. Jeong, J. R. Williams, (2014). Accounting for conceptual soil erosion and sediment yield modeling uncertainty in APEX model using Bayesian model averaging. Journal of Hydrologic Engineering. DOI: 10.1061/(ASCE)HE.1943-5584.0001119. C4014010.

White, M., D. Harmel, H. Yen, J. Arnold, M. Gambone, and R. Haney, (2015). Development of Sediment and Nutrient Export Coefficients for U.S. Ecoregions. Journal of the American Water Resources Association (JAWRA) 1-18. DOI: 10.1111/jawr.12270

Williams, J. W., R. C. Izaurralde, and E. M. Steglich., (2012). Agricultural Policy/Environmental EXtender Model Theoretical Documentation Version 0806. Page 131. 
Yen, H., Jeong, J., Tseng, W., Kim, M., Records, R., and Arabi, M., (2014a). Computational Procedure for Evaluating Sampling Techniques on Watershed Model Calibration. J. Hydrol. Eng. , 10.1061/(ASCE)HE.1943-5584.0001095 , 04014080.

Yen, H., Wang, X., Fontane, D. G., Harmel, R. D., Arabi, M., (2014b). A framework for propagation of uncertainty contributed by parameterization, input data, model structure, and calibration/validation data in watershed modeling, Environmental Modelling and Software, 54, pp. 211-221, doi: 10.1016/j.envsoft.2014.01.004.

Yen, H., Jeong, J., Feng, Q., Deb, D., (2015a). Assessment of input uncertainty in SWAT using latent variables, Water Resources Management, 29, pp. 1137-1153, doi:10.1007/s11269014-0865-y.

Yen, H., Sharifi, A., Kalin, L., Mirhosseini, G., Arnold, J. G., (2015b). Assessment of model predictions and parameter transferability by alternative land use data on watershed modeling, Journla of Hydrology, 527, pp. 458-470, doi:10.1016/j.jhydrol.2015.04.076.

Zhenyao, S., Lei, C., Tao, C., (2013). The influence of parameter distribution uncertainty on hydrological and sediment modeling: A case study of SWAT model applied to the Daning watershed of the Three Gorges Reservoir Region, China. Stochastic Environmental Research and Risk Assessment, 27(1), 235-251. doi: 10.1007/s00477-012-0579-8 


\section{$519 \quad$ ACKNOWLEGMENTS}

520 This project was funded by grants from the United States Department of Agriculture 521 Natural Resources Conservation Service (USDA-NRCS) Conservation Effects Assessment

522 Project (CEAP) - Wildlife and Cropland components. Please remember that USDA is an equal 523 opportunity employer and provider! 


\section{Appendix A}

539 Calibration parameters for all case scenarios

\begin{tabular}{|c|c|c|c|c|}
\hline Parameters & Input file & Units & Range & Description \\
\hline ADJ_PKR &.$b s n$ & - & $0.5-2$ & Peak rate adjustment factor for sediment routing in the subbasin (tributary channels) \\
\hline $\mathrm{CMN}$ &.$b s n$ & - & $0.001-0.003$ & Rate factor for humus mineralization of active organic nitrogen \\
\hline EPCO &.$b s n$ & - & $0-1$ & Plant uptake compensation factor \\
\hline NPERCO &.$b s n$ & - & $0-1$ & Nitrogen percolation coefficient \\
\hline PRF &.$b s n$ & - & $0-2$ & Peak rate adjustment factor for sediment routing in the main channel \\
\hline SPCON &.$b s n$ & - & $0.0001-0.01$ & Linear parameter for calculating the maximum amount of sediment that can be re-entrained during channel sediment routing \\
\hline SPEXP &.$b s n$ & - & $1-1.5$ & Exponent parameter for calculating sediment re-entrained in channel sediment routing \\
\hline SURLAG &.$b s n$ & Day & $1-24$ & Surface runoff lag time \\
\hline ALPHA_BF &. $\mathrm{gw}$ & 1/Day & $0-1$ & Baseflow alpha factor \\
\hline GW_DELAY &.$g w$ & Day & $0-500$ & Groundwater delay \\
\hline GW_REVAP &. $\mathrm{gw}$ & - & $0.02-0.2$ & Groundwater "revap" coefficient \\
\hline GWQMN &. $\mathrm{gw}$ & $\mathrm{mm} \mathrm{H}_{2} \mathrm{O}$ & $0-5000$ & Threshold depth of water in the shallow aquifer required for return flow to occur \\
\hline SLSUBBSN & .hru & M & $10-150$ & Average slope length \\
\hline CN_F & mgt & $\%$ & \pm 10 & Initial SCS CN II value \\
\hline CH_COV2 & .rte & - & $-0.001-1$ & Channel cover factor \\
\hline CH_K2 & .rte & $\mathrm{mm} / \mathrm{hr}$ & $-0.01-500$ & Effective hydraulic conductivity in main channel alluvium \\
\hline CH_N2 & .rte & - & $-0.01-0.3$ & Manning's " $n$ " value for the main channel \\
\hline SOL_AWC & .sol & $\%$ & \pm 10 & Available water capacity of the soil layer \\
\hline SOL_K & .sol & $\%$ & \pm 10 & Saturated hydraulic conductivity \\
\hline CH_K1 & sub & $\mathrm{mm} / \mathrm{hr}$ & $0-300$ & Effective hydraulic conductivity in tributary channel alluvium \\
\hline CH_N1 & sub & - & $0.01-30$ & Manning's "n" value for the tributary channels \\
\hline RS3 &.$s w q$ & $\mathrm{mg} / \mathrm{m}^{2}$-day & $0-1$ & Benthic source rate for NH4-N in the reach at $20^{\circ} \mathrm{C}$ \\
\hline RS4 & swq & 1/day & $0.001-0.1$ & Rate coefficient for organic $\mathrm{N}$ settling in the reach at $20^{\circ} \mathrm{C}$ \\
\hline
\end{tabular}

540 Parameter values for CN_F, SOL_AWC, SOL_K, USLE_K, and USLE_C are the changes of fraction from default values. 

and specific definitions

\begin{tabular}{|c|c|c|}
\hline Case Scenarios & Number of Latent Variables & Scenario Descriptions \\
\hline Scenario 01 & - & Case scenario with no latent variables applied \\
\hline Scenario 02 & $\mathrm{x} 2$ & $\begin{array}{l}\text { Same set of latent variables on both Dry/Wet seasons and all stations } \\
\text { (default settings of latent variables as the in Ajami et al. (2007)) }\end{array}$ \\
\hline Scenario 03 & $\mathrm{x} 4$ & $\begin{array}{l}\text { Latent variables are applied in Dry/Wet seasons (based on seasonal } \\
\text { Definition I) respectively, all three stations are sharing the same set of } \\
\text { latent variables }\end{array}$ \\
\hline Scenario 04 & $\mathrm{x} 4$ & $\begin{array}{l}\text { Latent variables are applied in Dry/Wet seasons (based on seasonal } \\
\text { Definition II) respectively, all three stations are sharing the same set of } \\
\text { latent variables }\end{array}$ \\
\hline Scenario 05 & $\mathrm{x} 12$ & $\begin{array}{l}\text { Latent variables are applied in Dry/Wet seasons (based on seasonal } \\
\text { Definition II) respectively, all three stations are using different sets of } \\
\text { latent variables }\end{array}$ \\
\hline
\end{tabular}
and validation are shown on the left and right side of the "/" sign).

\begin{tabular}{ccccccc}
\hline \multirow{2}{*}{ Scenarios } & \multicolumn{3}{c}{ Streamflow } & \multicolumn{2}{c}{ Sediment } & \multicolumn{2}{c}{ Ammonia } \\
\cline { 2 - 6 } & NSE & RPD (\%) & NSE & RPD (\%) & NSE & RPD (\%) \\
\hline Scenario 01 & $0.54 * / 0.55 * *$ & $12 / 4$ & $0.78 / 0.45$ & $0 / 0$ & $0.61 / 0.26$ & $5 / 51$ \\
\hline Scenario 02 & $0.61 / 0.56$ & $0 / 2$ & $0.75 / 0.27$ & $4 / 50$ & $0.64 / 0.19$ & $0 / 64$ \\
Scenario 03 & $0.57 / 0.52$ & $7 / 9$ & $0.76 / 0.44$ & $3 / 2$ & $0.56 / 0.39$ & $13 / 26$ \\
Scenario 04 & $0.57 / 0.49$ & $7 / 15$ & $0.76 / 0.39$ & $3 / 14$ & $0.59 / 0.47$ & $8 / 11$ \\
Scenario 05 & $0.58 / 0.57$ & $5 / 0$ & $0.73 / 0.45$ & $7 / 0$ & $0.59 / 0.53$ & $8 / 0$ \\
*: Error statistics for the calibration period (from 2002 to 2003) & & \\
**: Error statistics for the validation period (from 2004 to 2005) \\
- RPD is defined to provide supplementary indices in categorizing relative differences among various statistical results. \\
- The value of RPD is zero when the current state represents the best scenario.
\end{tabular}
ammonia, within the $95 \%$ confidence interval and corresponding spread for the simulation period 2002 to 2003.

\begin{tabular}{cccc|ccc}
\hline \multirow{2}{*}{ Scenario } & \multicolumn{3}{c|}{ Inclusion Rate (\%) } & \multicolumn{3}{c}{ Spread } \\
\cline { 2 - 7 } & Streamflow & Sediment & Ammonia & Streamflow & Sediment & Ammonia \\
\hline Scenario 01 & 49.59 & 62.50 & 91.67 & 1.815 & 0.044 & 0.147 \\
\hline Scenario 02 & 46.99 & 70.83 & 79.17 & 2.664 & 0.054 & 0.182 \\
Scenario 03 & 31.92 & 62.50 & 75.00 & 1.436 & 0.044 & 0.153 \\
Scenario 04 & 23.29 & 50.00 & 75.00 & 1.178 & 0.044 & 0.146 \\
Scenario 05 & 22.19 & 45.83 & 70.83 & 1.135 & 0.043 & 0.131 \\
\hline
\end{tabular}

Inclusion rate (\%): Percentage of observed data points located within the $95 \%$ confidence interval. Spread: Average width of the corresponding uncertainty band along the predicted time series. The units for streamflow, sediment, and ammonia are cms (cubic meter per second), ton/ha (tons per hectare), and $\mathrm{kg} / \mathrm{ha}$ (kilogram per hectare) respectively. 


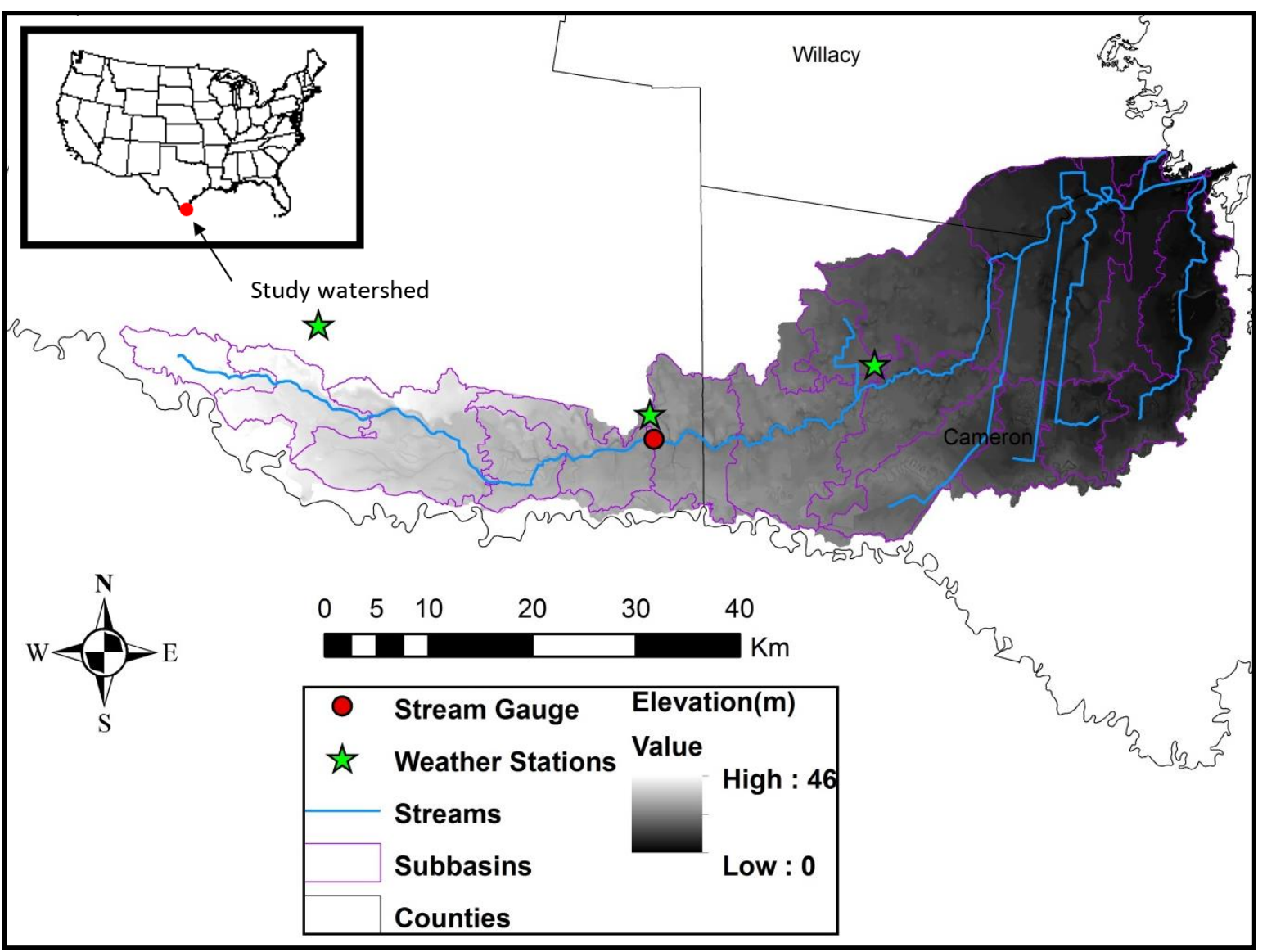

Figure 1. Arroyo Colorado Watershed stream gauge and weather station locations. 

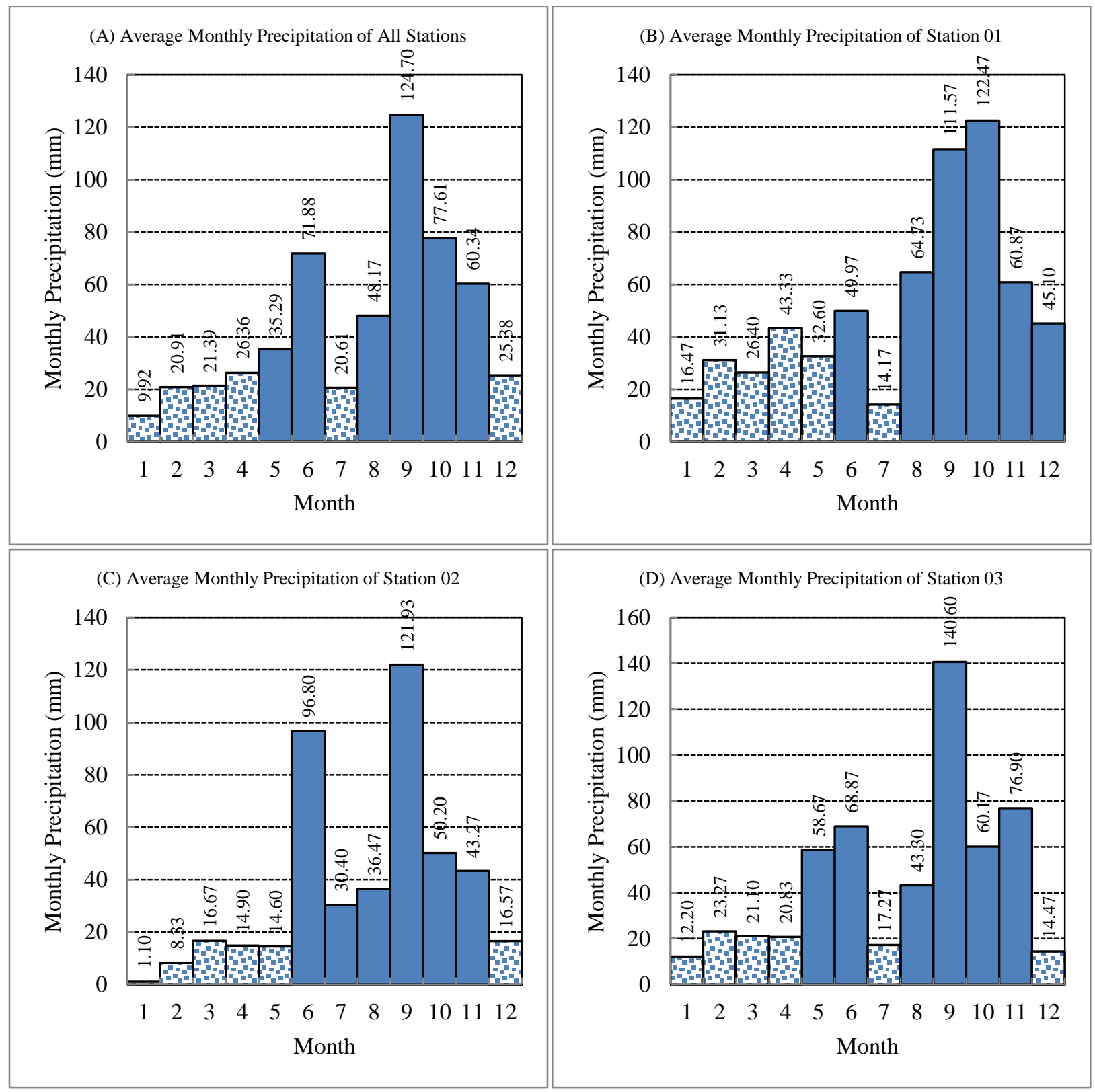

*: Solid bars represent six months with relatively higher (defined as a part of the wet season) average monthly precipitation in each figure. **: Dotted bars represent six months with relatively lower (defined as a part of the dry season) average monthly precipitation in each figure.

Figure 2. Average monthly precipitation used to categorize Dry/Wet seasons in case study: 


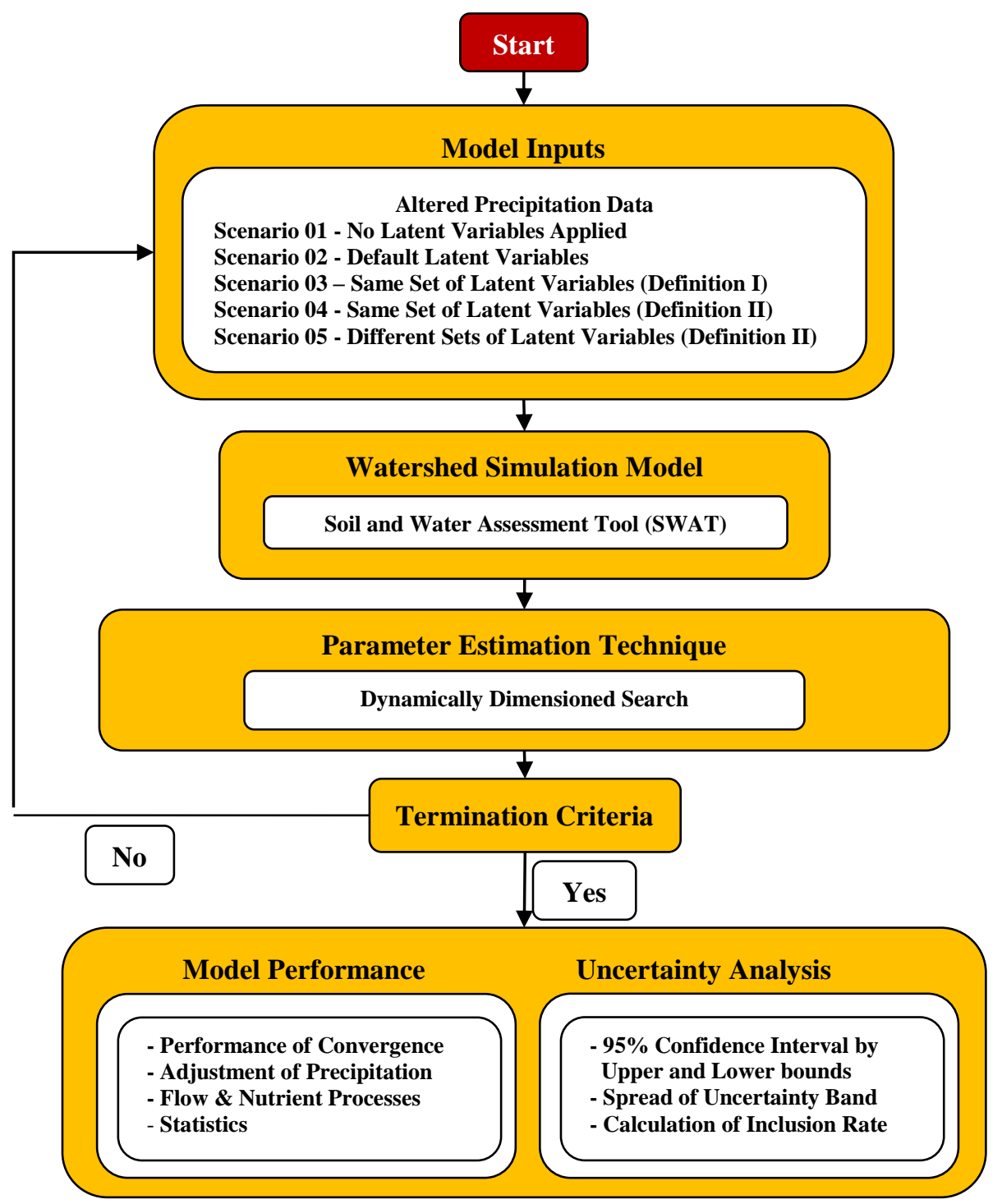

Figure 3. Organogram of IPEAT and the incorporation of input uncertainty on precipitation 


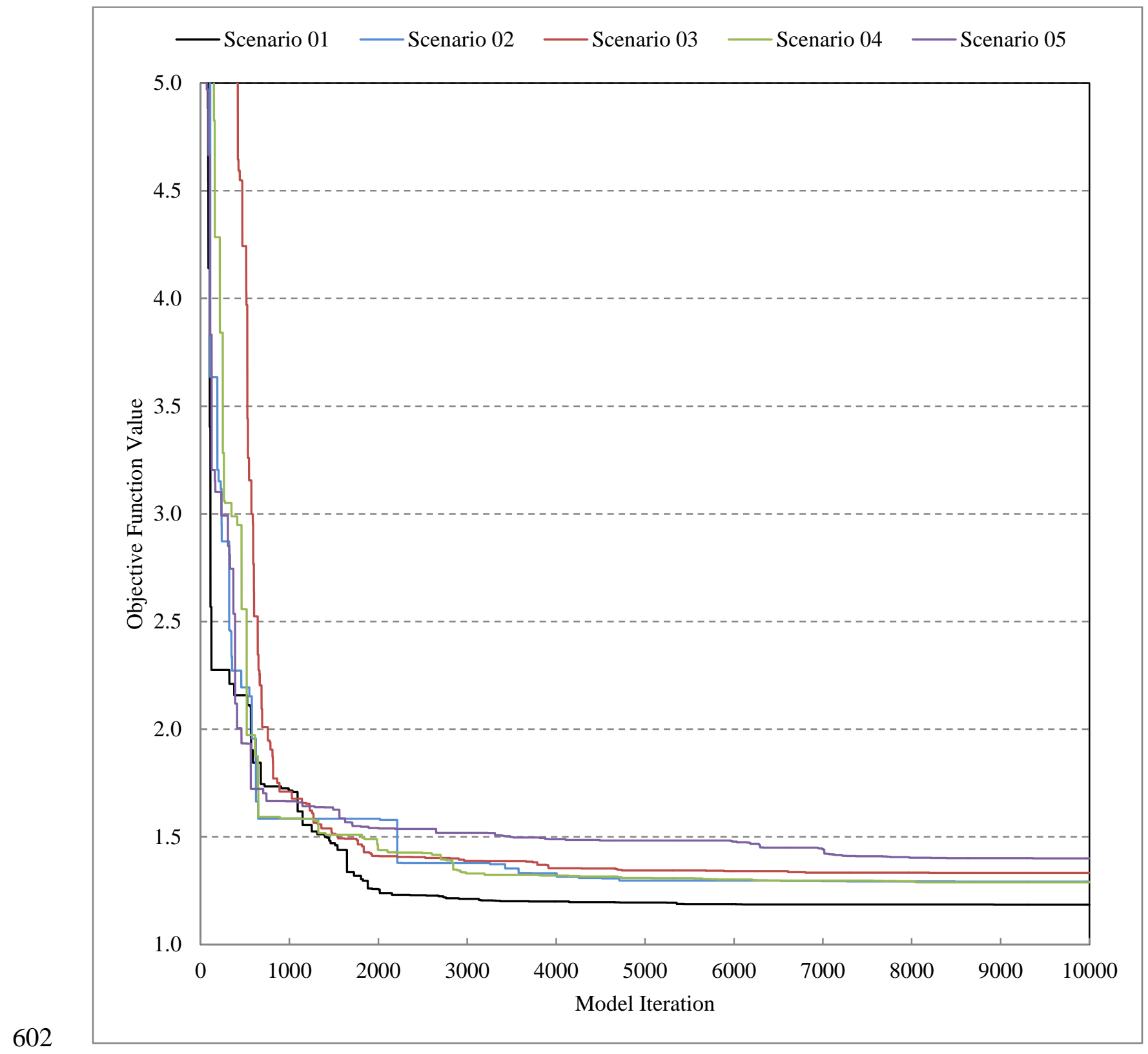

Figure 4. General model performance, as convergence of objective function values versus 


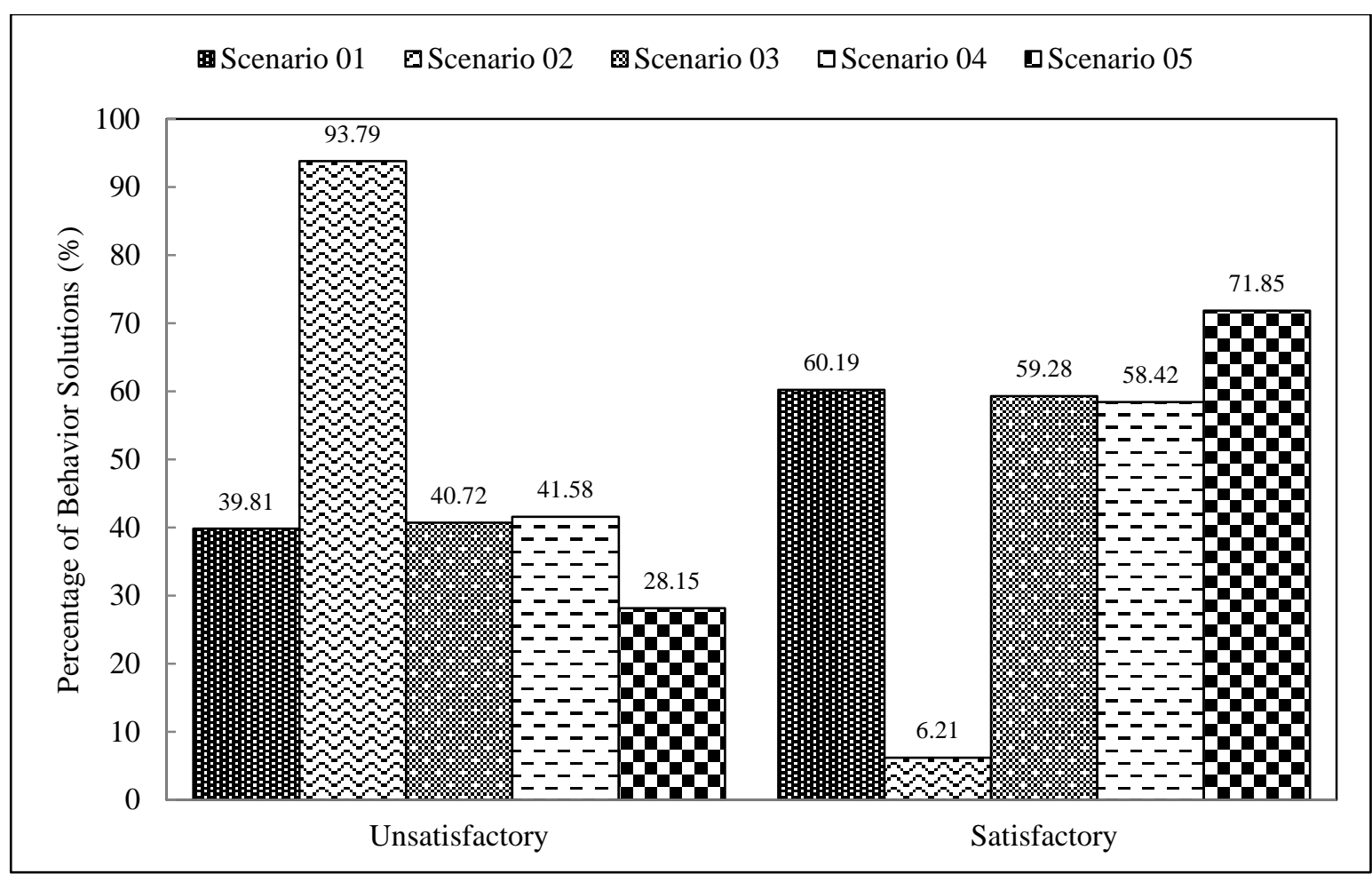

Figure 5. Rate of behavior solutions by implementing the General Performance Ratings 


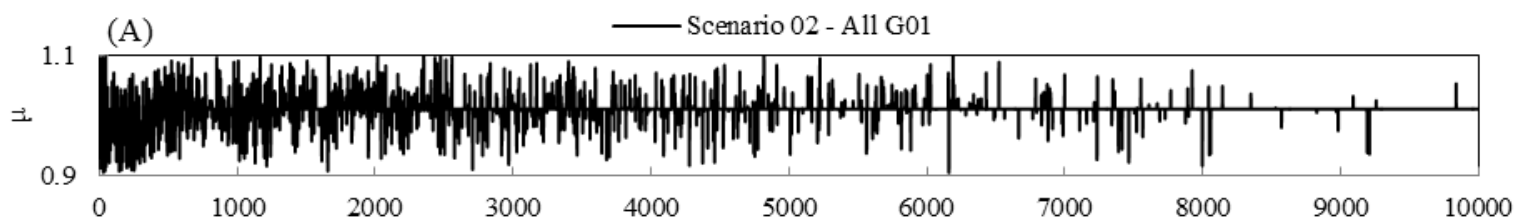

(B)

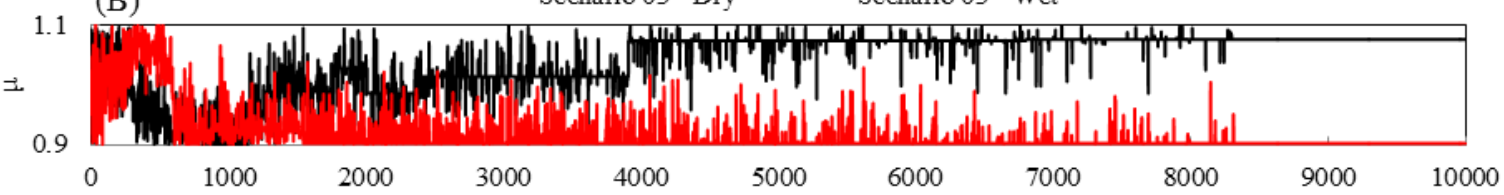

625

626
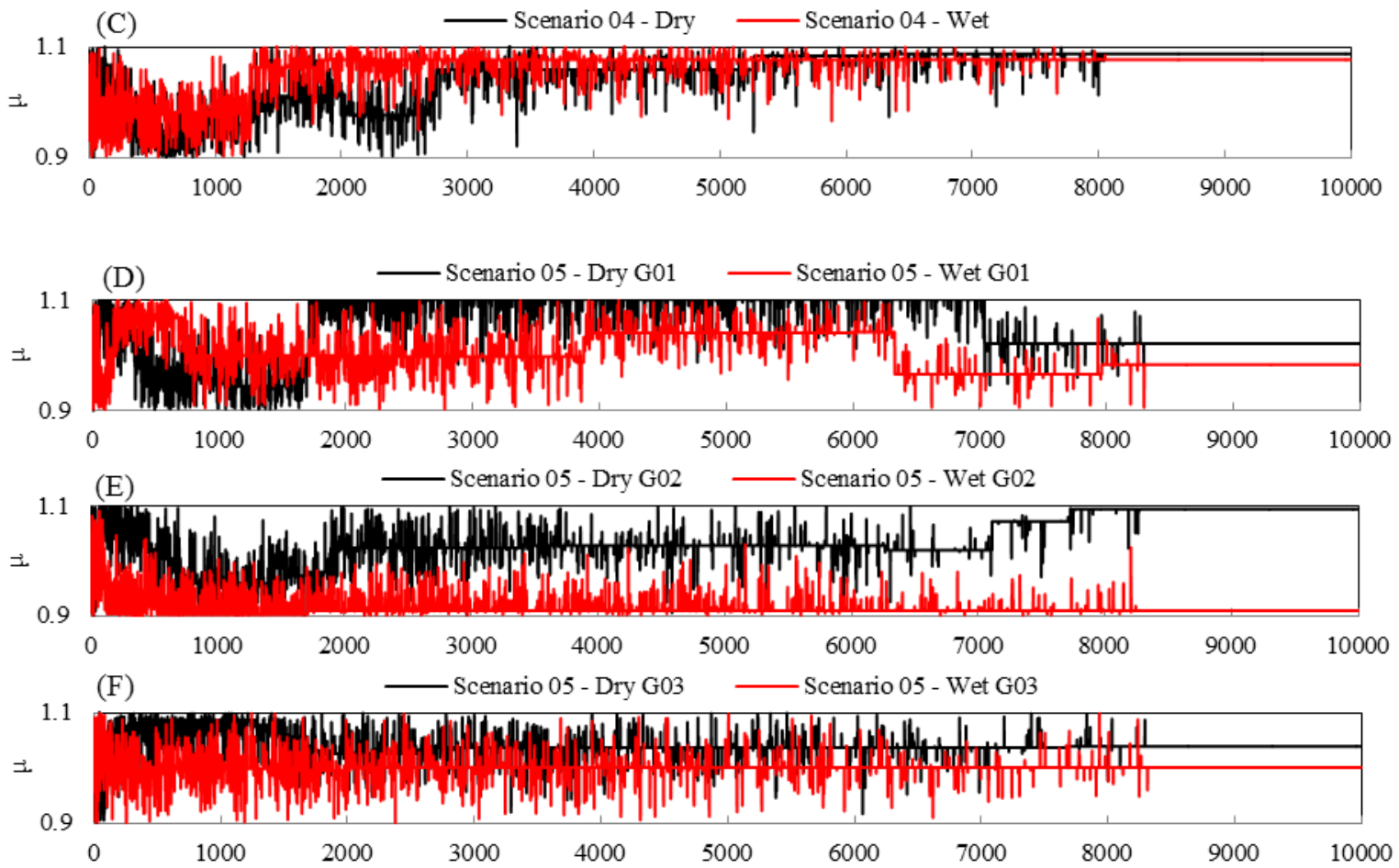

Definition I: Definition of Dry/Wet seasons is using average monthly precipitation for all stations (also see Figure 2)

631 Definition II: Definition of Dry/Wet seasons is using average monthly precipitation for each gauge station (also see Figure 2)

632 G: Gauge station

633 Figure 6. Convergence patterns of latent variables. Scenario 02, 03, and 04 are cases with 634 inclusion of latent variables during calibration): (A) same set of latent variables in both Dry/Wet 635 seasons; (B) latent variables applied to Dry/Wet seasons (based on Definition I) respectively on 636 all three gauge stations, using same set of latent variables; (C) latent variables applied in 637 Dry/Wet seasons (based on Definition II) respectively on all three gauge stations (using same set 638 of latent variables); and, (D) (F) latent variables applied in Dry/Wet seasons (based on 639 Definition II) respectively on all three gauge stations (using three sets of latent variables). 

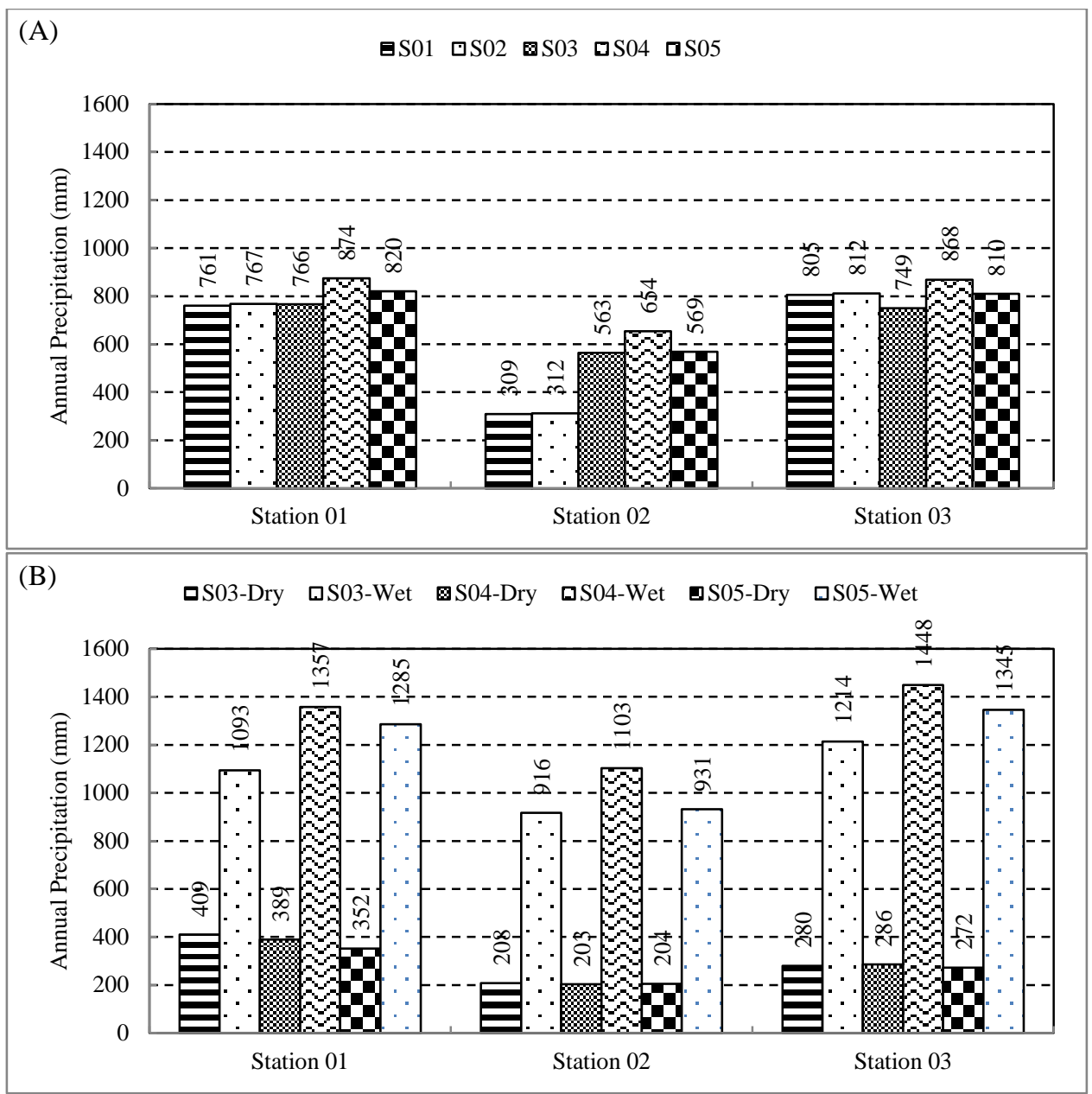

642

644

645

646

647

648

649

*: To better compare adjusted precipitation (precipitation is usually compared in average annual fashion), the adjusted seasonal precipitation was projected to be in a full year length. For example, the adjusted average daily precipitation of Scenario 03 on wet season is 2.99 (mm/day). Therefore, the projected average annual precipitation is $2.99 \times 365=1093(\mathrm{~mm} / \mathrm{day})$.

Figure 7. Original (Scenario 01) and adjusted average annual precipitation depth for Scenarios 15: (A) average annual precipitation; and (B) projected average annual precipitation in dry and wet seasons. 